\title{
Magnetic properties and NEXAFS-spectroscopy of Co-doped ferroelectric ceramic $\mathrm{Bi}_{5} \mathrm{Nb}_{3} \mathrm{O}_{15}$
}

\author{
N. A. Zhuk ${ }^{\dagger, 1}$, S. V. Nekipelov ${ }^{1,2}$, D. S. Beznosikov ${ }^{1}$, L. V. Rychkova ${ }^{1}$, \\ M. V. Yermolina ${ }^{3}$, B. A. Makeev ${ }^{4}$ \\ †nzhuck@mail.ru \\ ${ }^{1}$ Syktyvkar State University, 55 Oktyabrsky Av., Syktyvkar, 167001, Russia \\ ${ }^{2}$ Institute of Physics and Mathematics of the Komi Science Center UB RAS, 4 Oplesnina St., Syktyvkar, 167982, Russia \\ ${ }^{3}$ University of Illinois at Chicago, 845 W. Taylor St., MC 111, Chicago, IL, 60607, USA \\ ${ }^{4}$ Institute of Geology of the Komi Scientific Center UB RAS, 54 Pervomaiskaya St., Syktyvkar, 167982, Russia
}

\begin{abstract}
The majority of bismuth-containing compounds with a layered perovskite-like structure, analogues of the so-called Aurivillius phases, are of practical and theoretical interest owing to their ferroelectric properties. Bismuth niobate $\mathrm{Bi}_{5} \mathrm{Nb}_{3} \mathrm{O}_{15}$ belongs to the group of mixed layered compounds. Its structure is characterized by the ordered alternation of fragments formed by one and two niobium-oxygen octahedra. Magnetic properties and NEXAFS of cobalt-containing solid solutions with a layered perovskite-like structure $\mathrm{Bi}_{5} \mathrm{Nb}_{3-3 x} \mathrm{Co}_{3 x} \mathrm{O}_{15-\delta}$ have been studied. Solid solutions of $\mathrm{Bi}_{5} \mathrm{Nb}_{3-3 x} \mathrm{Co}_{3 x} \mathrm{O}_{15-\delta}(x \leq 0.005)$ can be crystallized in tetragonal syngony (sp.gr. $P 4 / \mathrm{mmm}$ ), as cobalt content increases, monoclinic distortion of the unit cell emerges at $0.005<x \leq 0.04$. The solid solutions as well as cobalt oxides $\mathrm{CoO}, \mathrm{Co}_{3} \mathrm{O}_{4}$ were studied by the NEXAFS spectroscopy. The analysis of the NEXAFS Co2p-spectra of cobalt-containing solid solutions and cobalt oxides revealed that the studied Co atoms were mainly in the +2 and +3 oxidation state. The isotherms of paramagnetic component of magnetic susceptibility of cobalt atoms in $\mathrm{Bi}_{5} \mathrm{Nb}_{3-3 x} \mathrm{Co}_{3 x} \mathrm{O}_{15-\delta}$ are typical for antiferromagnets. The effective magnetic moments of single cobalt atoms calculated by extrapolating concentration dependencies of $\left[\chi^{\mathrm{para}}(\mathrm{Co})\right]$ to infinite dilution of the solid solutions exceed pure-spin values and increase as the temperature increases from $6.18 \mu \mathrm{B}(90 \mathrm{~K})$ to $6.69 \mu \mathrm{B}(320 \mathrm{~K})$. The formation of exchangebound aggregates of $\mathrm{Co}(\mathrm{III})$ and $\mathrm{Co}(\mathrm{II})$ atoms predominantly with antiferromagnetic exchange types has been found in the solid solutions.
\end{abstract}

Keywords: ceramics, magnetic properties, NEXAFS-spectroscopy.

\section{Introduction}

The majority of bismuth-containing compounds with a layered perovskite-like structure, analogues of the so-called Aurivillius phases, are of practical and theoretical interest owing to their ferroelectric properties [1-3]. The composition of such compounds is described by the general formula $\left(\mathrm{Bi}_{2} \mathrm{O}_{2}\right)\left(\mathrm{A}_{n-1} \mathrm{~B}_{n} \mathrm{O}_{3 n+1}\right)$, where the bismuth-oxygen layers $\mathrm{Bi}_{2} \mathrm{O}_{2}$ consist of $\mathrm{BiO}_{4}$ pyramids bound to each other by base edges and $\mathrm{A}_{n-1} \mathrm{~B}_{n} \mathrm{O}_{3 n+1}$ are perovskite-like fragments consisting of $\mathrm{BO}_{6}$ octahedra bound by vertices. The large cations $\mathrm{A}$ are located in the cubic octahedral sites between them [4-9]. The coefficient $n$ in the formula corresponds to the number of $\mathrm{BO}_{6}$ octahedra forming the thickness of a perovskitelike fragment. Alongside with the layered compounds which contain the uniform perovskite-like fragments, there are the so-called mixed or hybrid layered compounds $\left(\mathrm{Bi}_{2} \mathrm{O}_{2}\right)\left(\mathrm{A}_{n-1} \mathrm{~B}_{n} \mathrm{O}_{3 n+1}\right) \ldots\left(\mathrm{Bi}_{2} \mathrm{O}_{2}\right)\left(\mathrm{A}_{m-1} \mathrm{~B}_{m} \mathrm{O}_{3 m+1}\right)$ [10-13]. Their structure consists of alternating perovskite-like fragments of various widths. Bismuth niobate $\mathrm{Bi}_{5} \mathrm{Nb}_{3} \mathrm{O}_{15}$ belongs to the group of mixed layered compounds [14-17]. Its structure is characterized by the ordered alternation of fragments formed by one and two niobium-oxygen octahedra. Therefore, its structurecanbedescribed as $\left(\mathrm{Bi}_{2} \mathrm{O}_{2}\right)\left(\mathrm{NbO}_{4}\right)\left(\mathrm{Bi}_{2} \mathrm{O}_{2}\right)\left(\mathrm{BiNb}_{2} \mathrm{O}_{7}\right)$, with $n=1$ and $m=3$. Oxygen-niobium octahedra are bound by side vertices and are arranged in the $a-b$ plane of the crystal, the $\mathrm{Nb}-\mathrm{O}-\mathrm{Nb}$ bond angle is $180^{\circ}$. The layers of the octahedra are separated by the bismuth-oxygen layers $\mathrm{Bi}_{2} \mathrm{O}_{2}$, formed by the $\mathrm{BiO}_{4}$ pyramids and joined by the base edges.

The present work discusses the results of the NEXAFSspectroscopy and static magnetic susceptibility measurements of the electron state and the nature of the exchange interactions between cobalt atoms in the solid solutions of bismuth niobate $\mathrm{Bi}_{5} \mathrm{Nb}_{3} \mathrm{O}_{15}$ with a layered perovskite-like structure, which were obtained by heterovalent substitution of niobium (V) with cobalt atoms (II).

\section{Experimental}

The synthesis of the solid solutions was carried out by the standard ceramic procedure from special-purity grade bismuth (III), niobium (V), and cobalt (II) oxides at 650, 850,950 and $1050^{\circ} \mathrm{C}$. The phase composition of the products was determined by means of electron scanning microscopy (using a Tescan VEGA 3LMN electron scanning microscope and a INCA Energy 450 energy-dispersive spectrometer) and $\mathrm{X}$-ray diffraction analysis using a DRON-4-13 diffractometer $\left(\mathrm{Cu}_{\mathrm{Ka}}\right.$ radiation). The cell unit parameters of solid solutions 
were calculated using the CSD software package [18]. The quantitative measurement of the composition of the samples of the solid solution was performed by atom-emission spectrometry (a SPECTRO CIROS ISP spectrometer). The accuracy of relative measurements was $5 \%$. The magnetic susceptibility of the samples of the solid solutions was measured by the Faraday method in the temperature range of $77-400 \mathrm{~K}$ at 16 fixed temperatures and at the magnetic field strength of 7240, 6330, 5230 and 3640 Oe. A semicommercial installation created in the laboratory of magnetochemistry of St. Petersburg State University and consisting of an electromagnet, an electronic balance, and cryostate was used for magnetic susceptibility measurements. The NEXAFS (near-edge X-ray absorption fine structure) of the Co2p-absorption spectra of the cobaltcontaining solid solutions and cobalt oxides was obtained using a synchrotron radiation source at the Russian-German beamline at BESSY-II (Berlin) [19]. All the spectra were recorded in the total electron yield (TEY) mode [20].

\section{Results and discussion}

The cobalt-containing solid solutions $\mathrm{Bi}_{5} \mathrm{Nb}_{3-3 x} \mathrm{Co}_{3 x} \mathrm{O}_{15-\delta}$ have been studied with $0.005 \leq x \leq 0.04$. Cobalt atoms, which are close in size to niobium $(\mathrm{V})$ atoms $\left[\mathrm{R}(\mathrm{Nb}(\mathrm{V}))_{\mathrm{c} . \mathrm{n}=6}=0.064 \mathrm{~nm}\right.$; $\mathrm{R}(\mathrm{Co}(\mathrm{III}))_{\mathrm{c.n}=6(\mathrm{~h} . \mathrm{s})}=0.0545 \mathrm{~nm} ; \mathrm{R}(\mathrm{Co}(\mathrm{III}))_{\mathrm{c} . \mathrm{n}=6(\mathrm{II.s})}=0.061 \mathrm{~nm}$; $\left.\mathrm{R}(\mathrm{Co}(\mathrm{II}))_{\mathrm{c.n}=6(\mathrm{~h} . \mathrm{s})}=0.065 \mathrm{~nm} ; \mathrm{R}(\mathrm{Co}(\mathrm{II}))_{\mathrm{c.n}=6(1 . \mathrm{s})}=0.0745 \mathrm{~nm}\right][21]$, isomorphously substitute octahedral cation sites in the perovskite layers. The single-phase nature of the samples was proved by the methods of scanning electron microscopy and X-ray analyses (Figs. 1,2). Solid solutions of $\mathrm{Bi}_{5} \mathrm{Nb}_{3-3 x} \mathrm{Co}_{3 x} \mathrm{O}_{15-\delta}(x \leq 0.005)$ can be crystallized in tetragonal syngony (sp.gr. $P 4 / \mathrm{mmm}$ ), unit cell parameters with $x=0.005$ are: $a=0.5464 \pm 0.0001, c=2.0933 \pm 0.0002 \mathrm{~nm}$ $\left(\mathrm{Bi}_{5} \mathrm{Nb}_{3} \mathrm{O}_{15}\right.$, sp.gr. P4/mmm, $\left.a=0.547, c=2.097 \mathrm{~nm}[12]\right)$; as cobalt content increases, monoclinic distortion of the unit cell emerges at $0.005<x \leq 0.04$. Monoclinic distortion of the tetragonal cell of the solid solutions $\mathrm{Bi}_{5} \mathrm{Nb}_{3} \mathrm{O}_{15}$ was established in previous works [12,22-24] and is associated with formation of atomic defects in the structure. The X-ray patterns of the solid solutions were interpreted based on the space group $P 2 / m$ [24]. The unit cell parameters with $x=0.04$ are: $a=0.5463 \pm 0.0005 \mathrm{~nm}, c=2.0843 \pm 0.0002 \mathrm{~nm}$, $b=0.5454 \pm 0.0008 \mathrm{~nm}$, the $a$ angle changes from $90^{\circ}$ to $90.67 \pm 0.01^{\circ}$.

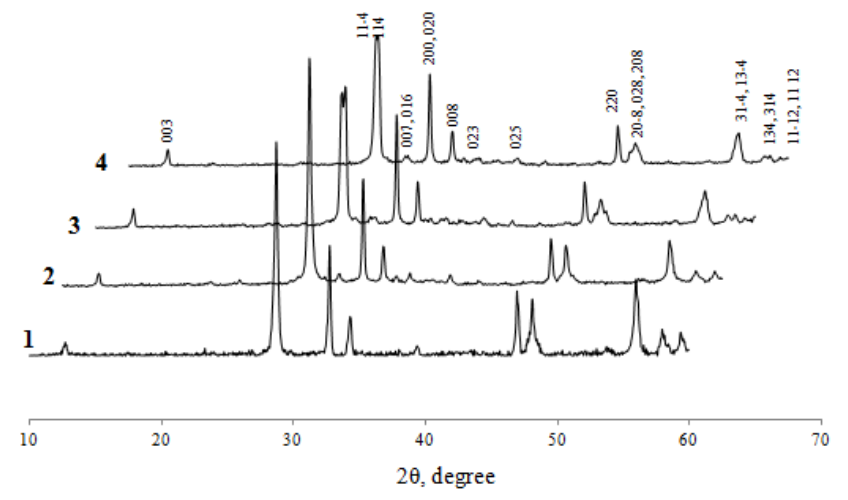

Fig. 1. $\mathrm{X}$-ray patterns of $\mathrm{Bi}_{5} \mathrm{Nb}_{3} \mathrm{O}_{15}$ (1) and the solid solutions $\mathrm{Bi}_{5} \mathrm{Nb}_{3-3 x} \mathrm{Co}_{3 x} \mathrm{O}_{15-\delta}$ at $x=0.005$ (2), 0.02 (3), 0.04 (4).

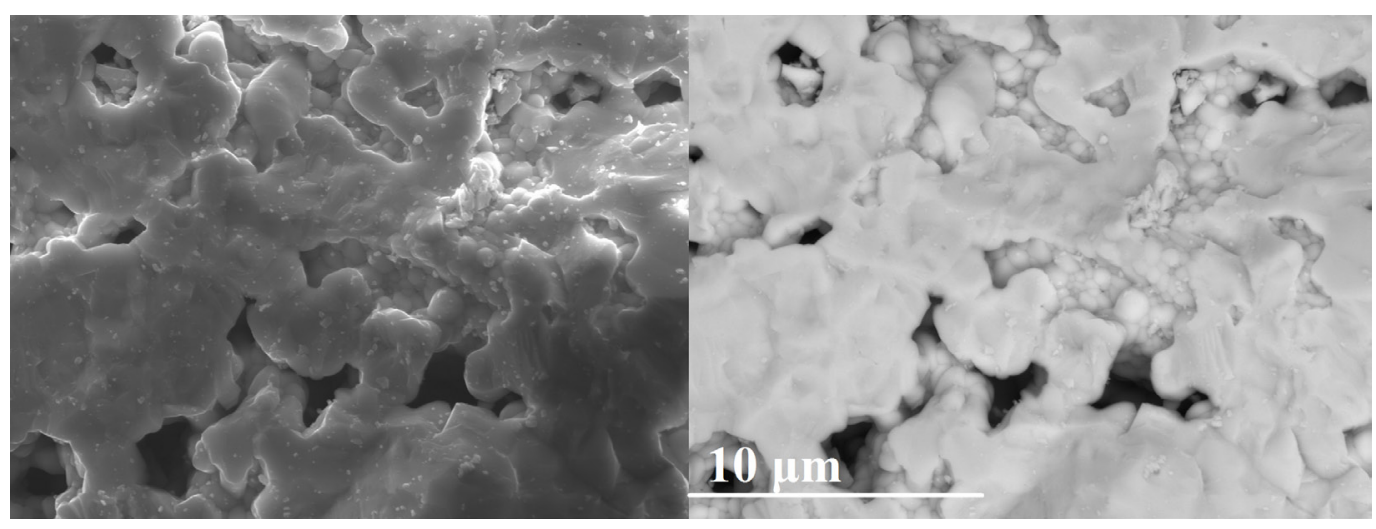

a

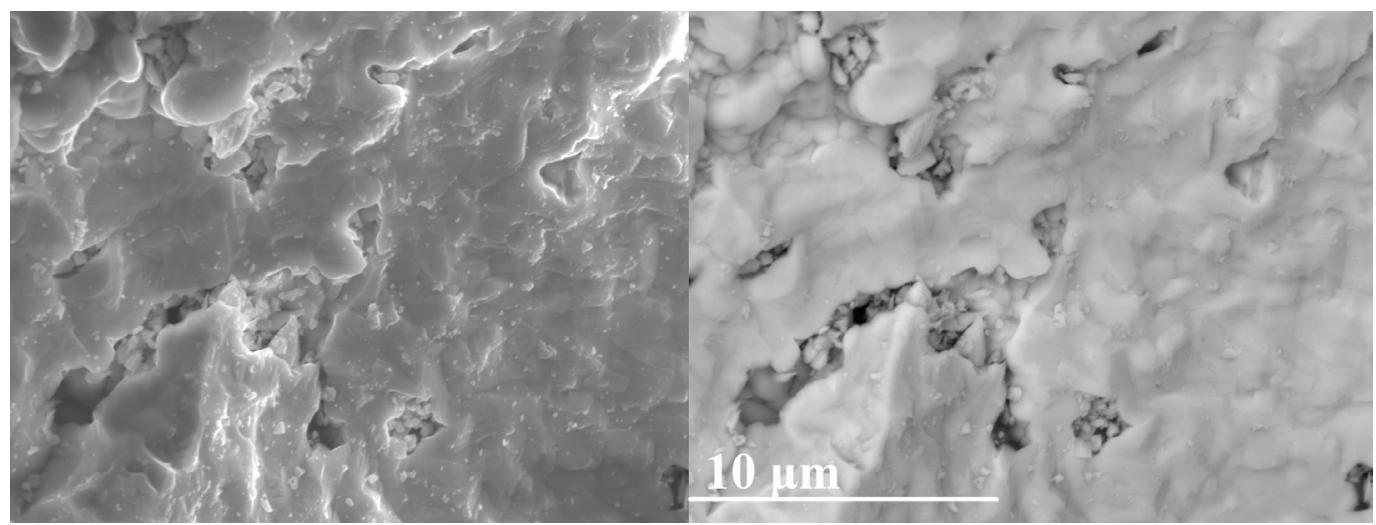

b

Fig. 2. Surface photomicrographs of the sample $\mathrm{Bi}_{5} \mathrm{Nb}_{3-3 x} \mathrm{Co}_{3 x} \mathrm{O}_{15-\delta}$ at $x=0.01$ (a) and 0.04 (b) in the mode of secondary and elastic backscattered electrons. 
Fig. 2 shows the surface of samples of $\mathrm{Bi}_{5} \mathrm{Nb}_{3-3 x} \mathrm{Co}_{3 x} \mathrm{O}_{15-\delta}$ $(x=0.01,0.04)$ obtained as secondary or elastically reflected electrons. Based on the data of the scanning electron microscopy, the samples are porous compacts with merged melted fine grains $1-3 \mu \mathrm{m}$.

The charge state of cobalt atoms in the samples of solid solutions was studied by means of NEXAFS spectroscopy at the synchrotron radiation source BESSY-II. The NEXAFS spectra were recorded in the total electron yield (TEY) mode. Fig. 3 shows the absorption spectra of cobalt atoms in bismuth niobate $\mathrm{Bi}_{5} \mathrm{Nb}_{3} \mathrm{O}_{15}$ against the spectra of $\mathrm{Co}_{3} \mathrm{O}_{4}$ and $\mathrm{CoO}$. As can be seen, the spectra of cobalt in bismuth niobate are most similar in intensity and energy position of the major peaks to the $\mathrm{Co} 2 \mathrm{p}_{3 / 2}$ - spectrum of $\mathrm{CoO}$ and to a lesser extent to the spectra of $\mathrm{Co}_{3} \mathrm{O}_{4}$. However, the broadband spectrum of cobalt in the solid solution and the ratio of intensities of the bands at $782 \mathrm{eV}$ and $779-780 \mathrm{eV}$ in it allowed us to present the spectrum of cobalt as a superposition of subspectra of cobalt from $\mathrm{CoO}$ and $\mathrm{Co}_{3} \mathrm{O}_{4}$, i.e. suggest the presence of cobalt atoms in two in oxidation states (II) and (III), with the higher peak in the region of $782 \mathrm{eV}$ being responsible for the $\mathrm{Co}^{3+}$ part, while the low-energy band $(779-780 \mathrm{eV})-$ for the $\mathrm{Co}^{2+}$ part. Based on the above, we can conclude that the charge state of cobalt atoms in $\mathrm{Bi}_{5} \mathrm{Nb}_{3} \mathrm{O}_{15}$ is +2 and +3 .

Using the measured magnetic susceptibility of the solid solutions, we calculated the paramagnetic components of the magnetic susceptibility and effective magnetic moments of cobalt atoms at various temperatures and concentrations of the solid solutions.

The isotherms of paramagnetic component of magnetic susceptibility of cobalt atoms in $\mathrm{Bi}_{5} \mathrm{Nb}_{3-3 x} \mathrm{Co}_{3 x} \mathrm{O}_{15-\delta}$ are typical for antiferromagnets, their comparison is shown in Fig. 4. The effective magnetic moments of single cobalt atoms calculated by extrapolating concentration dependencies of $\left[\chi^{\text {para }}(\mathrm{Co})\right]$ to infinite dilution of the solid solutions exceed pure-spin values and increase as the temperature increases from $6.18 \mu \mathrm{B}(90 \mathrm{~K})$ to $6.69 \mu \mathrm{B}(320 \mathrm{~K})$. The magnitude of the magnetic moment exceeds the pure spin values of high-spin cobalt atoms $\operatorname{Co}(\mathrm{II})\left(\mu_{\mathrm{eff}}=3.89 \mu \mathrm{B}\right)$ and $\mathrm{Co}(\mathrm{III})\left(\mu_{\mathrm{eff}}=4.92 \mu \mathrm{B}\right.$, therm ${ }^{5} \mathrm{E}_{\mathrm{g}}$ ), which may indicate the formation of exchangecoupled aggregates with the antiferromagnetic type of exchange out of cobalt atoms in infinitely dilute solid solutions.

The formation of aggregates out of paramagnetic atoms in highly dilute solutions did not turn out to be unexpected,

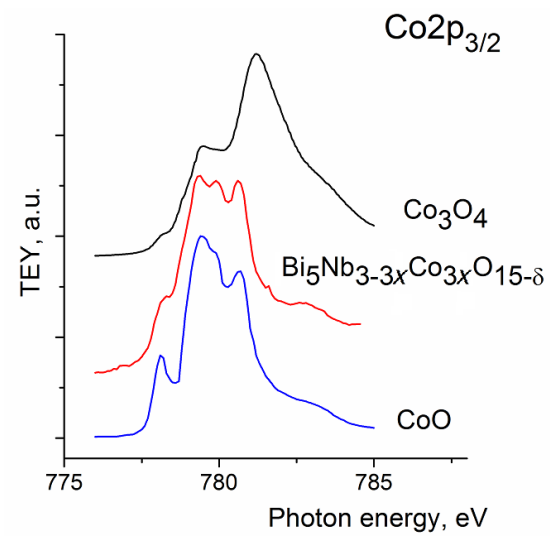

Fig. 3. NEXAFS Co2 $\mathrm{p}_{3 / 2}$-spectra of the $\mathrm{Bi}_{5} \mathrm{Nb}_{3-3 x} \mathrm{Co}_{3 x} \mathrm{O}_{15-\delta}$ at $x=0.04$ and cobalt oxides $\mathrm{CoO}$ and $\mathrm{Co}_{3} \mathrm{O}_{4}$. it was previously observed in solid solutions of $\mathrm{Bi}_{5} \mathrm{Nb}_{3} \mathrm{O}_{15}$ containing manganese or iron $[22,23]$ atoms and is displayed in case of distorted coordination polyhedron caused by heterovalent substitution. Monoclinic distortion of the tetragonal structure of the solid solutions of bismuth niobate associated with the incline of the crystallographic axis $c$ to the plane of perovskite layers indirectly indicates such distortions. Apparently, the formation of aggregates of paramagnetic atoms near the oxygen vacancies results in stabilization of the structure of the solid solutions.

The decrease in the paramagnetic component of the magnetic susceptibility of the atoms with increasing concentrations of solid solutions may be also associated with low-spin atoms of $\mathrm{Co}$ (III) $\left(\mu_{\text {eff }}=0 \mu \mathrm{B},{ }^{1} \mathrm{~A}_{1 \mathrm{~g}}\right)$ and an increase in the portion of cobalt clusters with an antiferromagnetic type of exchange between atoms [25]. The reduced magnitude of the magnetic moment in more concentrated solid solutions testifies in favour of the assumption of the described clustering. The dependence of the effective magnetic moment on cobalt atoms in solid solutions of various concentrations, growing with higher temperatures, indicates the antiferromagnetic type of exchange between atoms (Fig. 5). The antiferromagnetic type of exchange is supported by cobalt atom electrons in $d_{x^{2}-y^{2}}, d_{x y^{2}}, d_{x z^{2}}, d_{z^{2}}$ orbitals and layered perovskite structure of bismuth niobate ensuring indirect exchange between atoms at the angle of $180^{\circ}$ and accessibility of exchange channels $d_{x y}\left\|p_{y}\right\| d_{x y^{2}}, d_{x^{2}-y^{2}}\left\|p_{x}\right\| d_{x^{2}-y^{2}}$, $d_{x z}\left\|p_{z}\right\| d_{x z}, d_{x^{2}-y^{2}}\left\|p_{y}\right\| d_{x^{2}-y^{2}}$ and between the layers through the channel $-d_{x^{2}}\left\|p_{z}\right\| d_{z^{2}}$. Earlier, the validity of this assumption was shown by the example of iron-containing solid solutions with a layered perovskite structure [23], moreover, a conclusion was made on occupation of cationic positions of perovskite blocks in the layer-by-layer order. Partial ordering in the distribution of cations on different perovskite fragments was noted earlier by the authors [24] in the study of the $\mathrm{Bi}_{5} \mathrm{Nb}_{3} \mathrm{O}_{15}-\mathrm{Bi}_{5} \mathrm{Ti}_{1.5} \mathrm{~W}_{1.5} \mathrm{O}_{15}$ system. It was shown that tungsten atoms fill at first the cationic positions in the niobium-oxygen layers, which are one octahedron thick. After that, they are statistically distributed in the positions in the fragments with the thickness of two octahedra. The assumption of diamagnetic cobalt (III) atoms in concentrated solutions can be explained by a number of reasons. The oxidized state of cobalt is likely to reduce the destabilizing effect of oxygen vacancies on the structure of solid solutions; cobalt (III) atoms in the high-

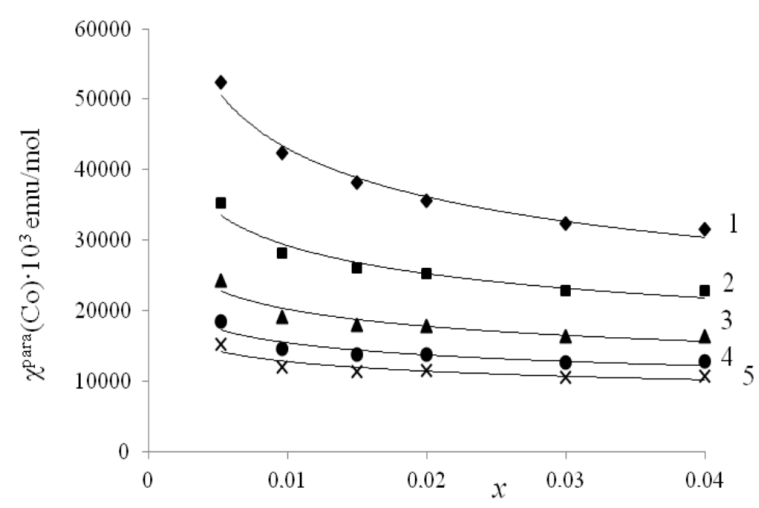

Fig. 4. Isotherms of paramagnetic component of magnetic susceptibility of the cobalt-containing solid solutions $\mathrm{Bi}_{5} \mathrm{Nb}_{3-3 x} \mathrm{Co}_{3 x} \mathrm{O}_{15-\delta}$ at $90 \mathrm{~K}$ (1), $140 \mathrm{~K}(2), 200 \mathrm{~K}(3), 260 \mathrm{~K}(4)$ and $320 \mathrm{~K}$ (5). 


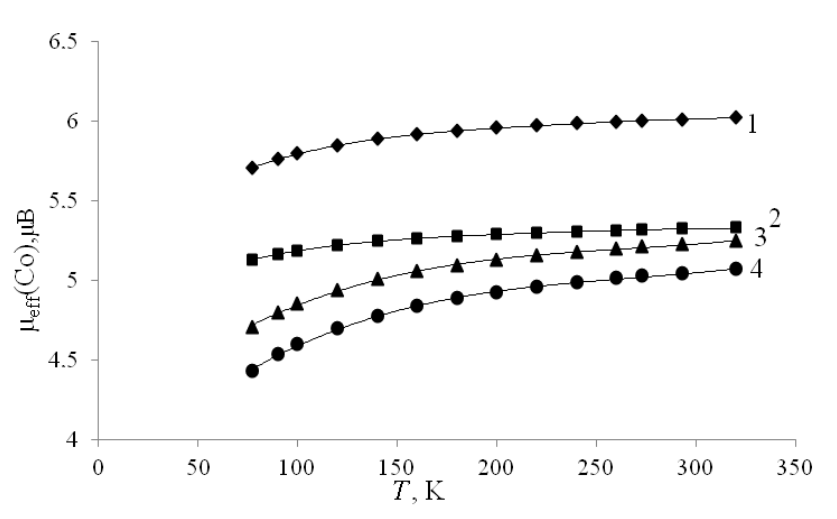

Fig. 5. Temperature dependencies of the effective magnetic moment of cobalt in the $\mathrm{Bi}_{5} \mathrm{Nb}_{3-3 x} \mathrm{Co}_{3 x} \mathrm{O}_{15-\delta}$ at $x=0.005$ (1), 0.01 (2), 0.02 (3) and $0.04(4)$.

spin state, with their significant magnetic moment cannot ensure such a sharp reduction of the magnetic susceptibility of solid solutions, and, moreover, the accumulated distortions of oxyden polyhedra caused by heterovalent substitution of $\mathrm{Nb}(\mathrm{V})$ atoms by cobalt atoms contribute to higher tension of the crystal field of paramagnetic atoms and the stabilized lowspin state of cobalt atoms.

In order to obtain additional data on the electronic state of cobalt in solid solutions EPR spectra of $\mathrm{Bi}_{5} \mathrm{Nb}_{3-3 x} \mathrm{Co}_{3 x} \mathrm{O}_{9}$ $(x=0.005,0.02,0.04)$ samples were studied. EPR spectra of all samples reflect the asymmetrical absorption band with $g=4.3$ (Fig. S1, Supplementary Material), associated with Co (II) $)_{s=3 / 2}$ based on the data of magneto-chemical studies and NEXAFS-spectroscopy, with its intensity decreasing due to higher cobalt content in solid solutions, which, according to [26], is caused by emergence of diamagnetic Co (III) atoms. The increased share of low-spin cobalt (III) atoms following a higher concentration of solid solutions was observed earlier for cobalt-containing solid solutions of lanthanum gallate and lanthanum strontium gallate. This assumption was supported by the results of the study of the EPR spectra of solid solutions with the observed reduction of integral intensity of the absorption band with $g$-factor 4.3 [26].

\section{Conclusions}

Thus, it was shown that the magnetic behavior of cobalt doping bismuth niobate solid solutions with a perovskite-like layered structure is generally similar and is determined mainly by the crystal structure of the solid solutions, the symmetry, and the strength of the crystal field formed by ligands. The cobalt (III), (II) atoms in solid solutions of heterovalent substitution aggregate forming strong clusters of cobalt atoms predominantly with the antiferromagnetic type of exchange, which not disintegrate even at infinite dilution. The analysis of the NEXAFS Co2p-spectra of cobalt-containing solid solutions and cobalt oxides revealed that the studied Co atoms were mainly in the +2 and +3 oxidation state, which correlates well with the magnetochemical study data.

Acknowledgements. The authors wish to thank Vladimir Pavlovich Lyutoev, Institute of Geology of the Komi Science Center of the Ural Branch of the Russian Academy of Sciences, for EPR studies.
Supplementary Material. The online version of this paper contains supplementary material (figure) available free of charge at the journal's Web site (lettersonmaterials.com)

\section{References}

1. G. A. Smolensky, V. A. Isupov, A. I. Agranovskaya. Soviet Physics Solid State. 3, 651 (1961). (in Russian)

2. V.A. Isupov. Ferroelectrics. 189, 211 (1996). Crossref

3. B. J. Macquart, B. J. Kennedy, T. Kamiyama, F. Izumi. J. Phys.-Condes. Matter. 16, 5443 (2004). Crossref

4. B. J. Kennedy, Q. Zhou, Ismunandar, Y. Kubota, K. Kato. J. Sol. St. Chem. 181, 1377 (2008). Crossref

5. R. Macquart, B. J. Kennedy, Y. Shimakawa. J. Sol. St. Chem. 160, 174 (2001). Crossref

6. C.H. Hervoches, P. Lightfoot. J.Sol. St. Chem. 153, 66 (2000). Crossref

7. Ismunandar, B. A. Hunter, B. J. Kennedy. Sol. St. Ion. 112, 281 (1998). Crossref

8. B. Aurivillius. Ark. Kemi. 54, 463 (1949).

9. Ismunandar, B. J. Kennedy, Gunawan, Marsongkohadi. J. Sol. St. Chem. 126, 135 (1996). Crossref

10. J. Gopalakrishnan, A. Ramanan, C.N.R. Rao, D. A. Jefferson D. A., Smith. J. Sol. St. Chem. 55, 101 (1984). $\underline{\text { Crossref }}$

11. A. Lisinska-Czekaj. J. Eur. Ceram. Soc. 24, 947 (2004). Crossref

12. T. Takenaka, K. Komura, K. Sakata. Ferroelectrics. Jpn. J. Appl. Phys. 35, 5080 (1996). Crossref

13. S. Tahara, A. Shimada, N. Kumada, Y. Sugahara. J. Sol. St. Chem. 180, 2517 (2007). Crossref

14. P. Boullay, L. Palatinus, N. Barrier. Inorgan. Chem. 52, 6127 (2013). Crossref

15. L. Chen, W. Guo, Y.X. Yang, A. Zhang, S. Q. Zhang, Y.H. Guo, Y.N. Guo. Phys. Chem. Chem. Phys. 15, 8342 (2013). Crossref

16. O. Depablos-Rivera, J. C. Medina, M. Bizarro, A. Martínez, A. Zeinert, S. E. Rodil. J. Alloys Compd. 695, 3704 (2017). Crossref

17. G. Steciuk, N. Barrier, A. Pautrat, P. Boullay. Inorgan. Chem. 57,3107 (2018). Crossref

18. L. G. Akselrud, Yu. N. Grin, P. Yu. Zavalij, V. K. Pecharsky, V.S. Fundamensky. Thes. Rep. XII Eur. Crystallographic. Meet. 3, 155 (1989).

19. J. Stöhr. NEXAFS Spectroscopy. Springer, Berlin (1992) 403 pp. $\underline{\text { Crossref }}$

20. T.J. Regan, H. Ohldag, C. Stamm, F. Nolting, J. Luning, J. Stöhr, R. L. White. Phys. Rev. B. 64, 214422 (2001). Crossref

21. R.D. Shannon. Acta Crystallogr. A. 32, 751 (1976). Crossref

22. N.A. Sekushin, N.A. Zhuk, E. A. Belyaeva, et al. Letters on Materials. 7, 393 (2017). Crossref

23. N. V. Chezhina, D. A. Korolev, A. V. Fedorova, et al. Russ. J. Gen. Chem. 87, 373 (2017). Crossref

24. N. A. Zhuk, N. V. Chezhina, V.A. Belyy, et al. Letters on Materials. 7, 402 (2017). Crossref

25. Yu. V. Rakitin. Introduction to magnetochemistry. The method of static magnetic susceptibility in chemistry. Moscow, Nauka (1980) 302 pp. (in Russian)

26. N.V. Chezhina, E. V. Zharikova, M.N. Knyazev. Russ. J. Gen. Chem. 80, 2399 (2010). rossref 